\title{
Thermochemical Study of Three Hindered Pyridine Derivatives
}

\author{
Vera L. S. Freitas, ${ }^{\dagger}$ William E. Acree, Jr., ${ }^{\dagger}$ and Maria D. M. C. Ribeiro da Silva ${ }^{*}, \dagger$ \\ Centro de Investigação em Química, Departamento de Química, Faculdade de Ciências, Universidade do Porto, Rua do Campo \\ Alegre, 687, P-4169-007 Porto, Portugal, and Department of Chemistry, University of North Texas, Denton, Texas 76203-5070
}

The present work reports the values of the gaseous standard $\left(p^{\circ}=0.1 \mathrm{MPa}\right)$ molar enthalpy of formation of three pyridine derivatives substituted with one, two, and three tert-butyl groups, in positions para, orthoortho and ortho-para-ortho to the nitrogen, respectively. The standard molar energies of combustion of each compound, determined by static bomb calorimetry, yielded their standard molar enthalpies of formation in the condensed phase at $T=298.15 \mathrm{~K}$, which together with the values of the standard molar enthalpies of vaporization or sublimation, measured by Calvet microcalorimetry, allowed the calculation of the standard gas phase molar enthalpy of formation of each compound studied. The enthalpies of combustion for 4-tertbutylpyridine (1), 2,6-di-tert-butylpyridine (1) and 2,4,6-tri-tert-butylpyridine (cr) were found to be, respectively, $-(5370.1 \pm 3.4) \mathrm{kJ} \mathrm{mol}^{-1},-(7954.2 \pm 4.0) \mathrm{kJ} \mathrm{mol}^{-1}$, and $-(10542.9 \pm 4.9) \mathrm{kJ} \mathrm{mol}^{-1}$. The molar enthalpies of vaporization were measured as $(54.4 \pm 1.3) \mathrm{kJ} \mathrm{mol}^{-1}$ for 4-tert-butylpyridine, $(56.6 \pm 1.2) \mathrm{kJ}$ $\mathrm{mol}^{-1}$ for 2,6-di-tert-butylpyridine, whereas the enthalpy of sublimation of 2,4,6-tri-tert-butylpyridine was found to be $(78.3 \pm 1.7) \mathrm{kJ} \mathrm{mol}^{-1}$.

\section{Introduction}

The molecular structure of an important class of the nitrogen heterocyclic compounds having one $\mathrm{sp}^{2}$-hybridized nitrogen atom as part of a ring, in addition to $\mathrm{sp}^{2}$-hybridized carbon results in pyridine, the simplest azabenzene, whose electronic structure is strongly perturbed by the presence of the electronegative nitrogen atom. Although the third $\mathrm{sp}^{2}$ orbital in each carbon atom is used for the linking with the hydrogen atom, that corresponding orbital for the nitrogen atom contains a pair of electrons in the molecular plane of the ring. Consequently, the more electronegative nitrogen atom compared to the carbon atoms does not donate electronic density to the ring $\pi$-system but withdraws electronic density from it, both inductively and by resonance. In fact, the resonance structures of pyridine, combined with the knowledge of the protonic chemical shifts, confirm that the nitrogen atom removes electronic density from the ortho positions, by inductive and resonance effects, whereas only the resonance effect is present at the para position. ${ }^{1}$

Pyridine is a simple and fundamentally important aromatic heterocyclic organic compound and its derivatives are industrially important in applications ranging from the development of new pesticides to the production of new pharmaceutical drug molecules and new products in the petrochemical industry. ${ }^{2}$ The breaking and making of chemical bonds involved in chemical processes justifies the need for thermochemical data of key compounds from which it should be possible to predict data for unstudied related compounds.

The systematic study of thermochemical properties of pyridine derivatives, both in the condensed and gaseous phases, is one of the subjects of our research work. For several years we have studied the thermochemical properties of various pyridine compounds in order to establish how the transferability of bond

\footnotetext{
* Corresponding author. E-mail: mdsilva@fc.up.pt. Phone: +351 220402

538. Fax: +351220402522.

Universidade do Porto.

$\stackrel{*}{*}$ University of North Texas.
}

energy contributions applies to these compounds ${ }^{3-17}$ and, consequently, to correlate their behavior in terms of energetics, structure and reactivity. In addition we have been examining the effect of different substituents on the dissociation enthalpy of the $(\mathrm{N}-\mathrm{O})$ bond of the nitrogen $\mathrm{N}$-oxide heterocycles, a study that requires the knowledge of thermochemical data of the correspondent heterocycles not having the $(\mathrm{N}-\mathrm{O})$ bond. ${ }^{18}$

This work is a study of the effects of the bulky tert-butyl substituents on the pyridinic ring and reports the calorimetric study of the three compounds, represented in figure 1: the liquids 4-tert-butylpyridine (4tBuPy) and 2,6-di-tert-butylpyridine (2,6dt$\mathrm{BuPy})$ and the solid 2,4,6-tri-tert-butylpyridine (2,4,6ttBuPy). The standard molar enthalpies of formation in the gaseous state of the three pyridine derivatives were derived from their standard molar energies of combustion, measured by static bomb calorimetry, and the correspondent standard molar enthalpies of vaporization or sublimation, measured by Calvet microcalorimetry.

These hindered substituted pyridine derivatives have received a large attention due their relevant applications; the monossubstituted compound has been widely used as an additive in the electrolyte solution of a new class of low-cost photovoltaic cells, called Grätzel cells, ${ }^{19-24}$ and the disubstituted compound is used in the production of homopolymers, copolymers or block copolymers. ${ }^{25}$ Available information regarding 2,4,6-tri-tertbutylpyridine is scarce probably due to the instability of this compound whose storage and handling requires an inert atmosphere. ${ }^{26}$

\section{Experimental Section}

Purification of the Samples. The compounds 4-tert-butylpyridine (purity $99 \%$, CAS 3978-81-2) and 2,6-di-tert-butylpyridine (purity $98.5 \%$, CAS 585-48-8) were obtained commercially from Sigma-Aldrich. Both compounds were purified by repeated fractional distillation over $\mathrm{KOH}$, under reduced pressure (boiling points, respectively, $338 \mathrm{~K}$ at $p=1 \mathrm{kPa}$ and 


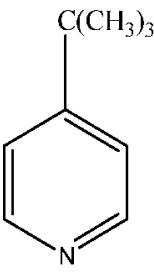

a)

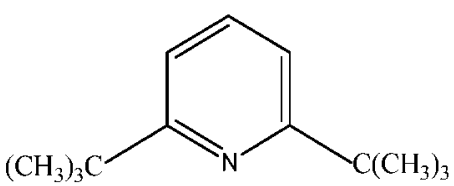

b)

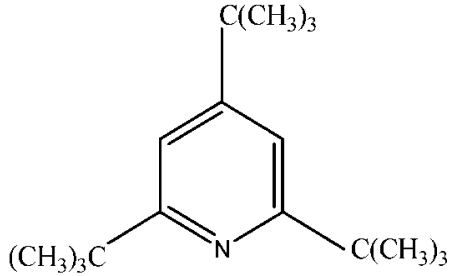

c)

Figure 1. Molecular structures for (a) 4-tert-butylpyridine; (b) 2,6-di-tert-butylpyridine; (c) 2,4,6-tri-tert-butylpyridine.

$359 \mathrm{~K}$ at $p=1.5 \mathrm{kPa}$ ), their purities being checked by glc (using an HP 4890 apparatus with a column HP-5, $5 \%$ diphenyl and $95 \%$ dimethylpolysiloxane, under a nitrogen pressure of 21 $\mathrm{kPa}$, and the temperature of the oven $423 \mathrm{~K}$ ) and also by the percentage of $\mathrm{CO}_{2}$ recovered in the combustion experiments; molar fraction purity 0.999 .

2,4,6-Tri-tert-butylpyridine (purity 99.2\%, CAS 20336-156) was obtained commercially also from Sigma-Aldrich. The compound has been submitted to additional purification, by sublimation under reduced pressure, immediately before the calorimetric measurements. The melting point measured in a melting point apparatus, Stuart Scientific SMP2, is $340 \mathrm{~K}$ to $342 \mathrm{~K}$. The DSC thermogram did not show any phase transitions before the melting temperature; molar fraction purity 0.998 .

The average ratios of the mass of carbon dioxide recovered to that calculated from the mass of sample, together with the standard deviation of the mean, were 4tBuPy, (1.0001 \pm 0.0004); 2,6dtBuPy, (0.9997 \pm 0.0003$)$; 2,4,6ttBuPy, (1.0004 $\pm 0.0005)$. The densities of the samples are $4 \mathrm{tBuPy}, \rho=0.915$ $\mathrm{g} \cdot \mathrm{cm}^{-3.26} 2,6 \mathrm{dtBuPy}, \rho=0.852 \mathrm{~g} \cdot \mathrm{cm}^{-3.26}$ and that of $2,4,6 \mathrm{ttBuPy}$ (estimated from the weight and volume of a pellet), $\rho=1.09 \mathrm{~g} \cdot \mathrm{cm}^{-3}$.

Static Bomb Calorimetry. The massic energies of combustion of the compounds were measured using a static bomb calorimeter equipped with a twin valve bomb of internal volume of $0.290 \mathrm{dm}^{3}$, previously described. ${ }^{27-29}$

The calorimetric system was calibrated using benzoic acid (NBS Standard Reference Material 39j) with a massic energy of combustion under standard bomb conditions of $-(26434$ $\pm 3) \mathrm{J} \cdot \mathrm{g}^{-1}$. The calibration results were corrected to give the energy equivalent $\varepsilon(\mathrm{cal})$ corresponding to the average mass of water added to the calorimeter, $2900.0 \mathrm{~g}$. Calibration experiments were made in oxygen at $p=3.04 \mathrm{MPa}$, with $1.00 \mathrm{~cm}^{3}$ of deionized water added to the bomb, leading to the values of the energy equivalent of the calorimeter, $\varepsilon(\mathrm{cal})$ $=(15553.3 \pm 0.9) \mathrm{J} \cdot \mathrm{K}^{-1}$ for the study of $4 \mathrm{tBuPy}$ and $\varepsilon(\mathrm{cal})$ $=(15546.3 \pm 1.3) \mathrm{J} \cdot \mathrm{K}^{-1}$ for the study of $2,6 \mathrm{dtBuPy}$ and $2,4,6 \mathrm{ttBuPy}$; the uncertainties quoted are the standard deviations of the mean.

The compounds were enclosed in polyester bags made of Melinex, $\left[\Delta_{\mathrm{c}} u^{\circ}=-\left(22902 \pm 5 \mathrm{~J} \cdot \mathrm{g}^{-1}\right)\right.$, a value confirmed by combustion of Melinex samples in our laboratory], using the technique described by Skinner and Snelson. ${ }^{30}$ The mass of Melinex used in each experiment was corrected for the mass fraction of water (0.0032) and the mass of carbon dioxide produced from it was calculated using the factor previously reported. ${ }^{30}$ The samples were ignited at $T=(298.150 \pm 0.001)$ $\mathrm{K}$ in oxygen at $p=3.04 \mathrm{MPa}$ with $1.00 \mathrm{~cm}^{3}$ of deionized water added to the bomb. The electrical energy for ignition $\Delta U$ (ign) was determined from the change in potential difference across a $1400 \mu \mathrm{F}$ condenser when discharged through the platinum ignition wire. Temperature measurements were automatically collected every ten seconds and the initial temperature of the combustion experiments was $298.15 \mathrm{~K}$ to which the energy of reaction was always referred. The combustion products were analyzed after the calorimetric measurements; the carbon dioxide was collected in absorption tubes and the amount of nitric acid determined by titration. The corrections for nitric acid formation were based on $-59.7 \mathrm{~kJ} \cdot \mathrm{g}^{-1}$ for the molar energy of formation of $0.1 \mathrm{~mol} \cdot \mathrm{dm}^{-3} \mathrm{HNO}_{3}(\mathrm{aq})$ from $\mathrm{N}_{2}(\mathrm{~g}), \mathrm{O}_{2}(\mathrm{~g})$ and $\mathrm{H}_{2} \mathrm{O}(\mathrm{l}){ }^{31}$ For the cotton thread fuse, $-\Delta_{\mathrm{c}} u^{\circ}=16250 \mathrm{~J} \cdot \mathrm{g}^{-1},{ }^{32}$ a value previously confirmed in our laboratory. The values for the pressure coefficient of specific energy, $(\partial u / \partial p)_{T}$, were assumed to be $-0.2 \mathrm{~J} \cdot \mathrm{g}^{-1} \cdot \mathrm{MPa}^{-1}$ at $T=298.15 \mathrm{~K}$, typical values for most organic compounds. ${ }^{33}$

The mass of compound, $m$ (compound), used in each experiment was determined from the total mass of carbon dioxide produced after allowance for that formed from the cotton thread fuse and Melinex. The standard massic energy of combustion, $\Delta_{\mathrm{c}} u^{\circ}$, was calculated by the procedure given by Hubbard et al. ${ }^{34}$

Calvet Microcalorimetry. The enthalpies of vaporization were determined in a Calvet high temperature microcalorimeter (SETARAM HT1000D), using a technique previously described $^{35}$ identical to that described for the measurements of enthalpies of sublimation, the "vacuum-sublimation drop microcalorimetric method". 36 The liquid samples of about $6 \mathrm{mg}$ to $9 \mathrm{mg}$ in a thin glass capillary tube sealed at one end were dropped at room temperature into the hot reaction vessel in the microcalorimeter, held at $T=365 \mathrm{~K}$ and $T=324 \mathrm{~K}$, for $4 \mathrm{tBuPy}$ and 2,6dtBuPy, respectively, and then removed from the hot zone by vacuum vaporization. The enthalpy of sublimation of $2,4,6 \mathrm{ttBuPy}$ was measured at $T=329 \mathrm{~K}$. The thermal corrections for the glass capillary tubes were evaluated and reduced in each run, by dropping empty tubes of nearly equal mass, on both calorimeter cells; $\Delta_{298.15}^{\mathrm{T}} H_{\mathrm{m}}^{\mathrm{o}}(\mathrm{g})$ was estimated by a group method based on the values of Stull et al. ${ }^{37}$ The microcalorimeter was calibrated in situ using the reported standard molar enthalpies of vaporization for decane ${ }^{38}$ and of sublimation for naphthalene. ${ }^{39}$

The relative atomic masses used throughout this paper were those recommended by the IUPAC Commission. ${ }^{40}$

\section{Results}

The results for a typical individual combustion experiment of each compound are given in Table 1 , where $\Delta m\left(\mathrm{H}_{2} \mathrm{O}\right)$ is the deviation of the mass of water added to the calorimeter from $2900.0 \mathrm{~g}$, the mass assigned for $\varepsilon(\mathrm{cal}) ; \Delta U_{\Sigma}$ is the correction to the standard state; $c_{p}\left(\mathrm{H}_{2} \mathrm{O}, 1\right)$ is the heat capacity of liquid water, $\varepsilon_{\mathrm{f}}$ is the energy of the bomb contents after ignition, $\Delta T_{\text {ad }}$ is the temperature rise, corrected for heat exchange and the energy of stirring, and $\Delta U_{\text {ign }}$ is the energy associated with the ignition. The solid and liquid samples were ignited at $T=298.15 \mathrm{~K}$ and 
Table 1. Typical Combustion Experiments at $T=298.15 \mathrm{~K}$

\begin{tabular}{|c|c|c|c|}
\hline & 4tBuPy & 2,6dtBuPy & 2,4,6ttBuPy \\
\hline$m\left(\mathrm{CO}_{2}\right.$, total $) / \mathrm{g}$ & 1.23479 & 1.27768 & 1.27098 \\
\hline$m$ (compound)/g & 0.37832 & 0.38590 & 0.36176 \\
\hline$m($ Melinex $) / g$ & 0.05402 & 0.05281 & 0.07555 \\
\hline$m($ fuse $) / g$ & 0.00172 & 0.00168 & 0.00250 \\
\hline$\Delta T_{\mathrm{ad}} / \mathrm{K}$ & 1.04754 & 1.11068 & 1.10470 \\
\hline$\varepsilon_{\mathrm{f}} /\left(\mathrm{JK}^{-1}\right)$ & 14.34 & 14.56 & 13.49 \\
\hline$\Delta m\left(\mathrm{H}_{2} \mathrm{O}\right) / \mathrm{g}$ & -1.4 & +0.7 & -0.3 \\
\hline$-\Delta U(\mathrm{IBP})^{a} / \mathrm{J}$ & 16300.67 & 17285.77 & 17186.88 \\
\hline$\Delta U($ Melinex $) / \mathrm{J}$ & 1237.27 & 1209.40 & 1730.26 \\
\hline$\Delta U($ fuse $) / \mathrm{J}$ & 27.93 & 27.28 & 40.60 \\
\hline$\Delta U\left(\mathrm{HNO}_{3}\right) / \mathrm{J}$ & 23.53 & 10.46 & 17.47 \\
\hline$\Delta U($ ign $) / \mathrm{J}$ & 0.92 & 0.62 & 0.63 \\
\hline$-\Delta U_{\Sigma} / \mathrm{J}$ & 7.62 & 7.18 & 6.13 \\
\hline$-\Delta_{\mathrm{c}} u^{\circ} /\left(\mathrm{J} \cdot \mathrm{g}^{-1}\right)$ & 39660.39 & 41519.69 & 42548.71 \\
\hline
\end{tabular}

Table 2. Individual Values of the Massic Energy of Combustion, $\Delta_{\mathrm{c}} u^{\circ}$, at $T=298.15 \mathrm{~K}$

\begin{tabular}{ccc}
\hline 4 tBuPy & $2,6 \mathrm{dtBuPy}$ & $2,4,6 \mathrm{ttBuPy}$ \\
\hline 39688.40 & 41482.62 & 42530.89 \\
39700.58 & 41496.37 & 42548.71 \\
39694.02 & 41527.47 & 42528.58 \\
39620.73 & 41522.89 & 42538.60 \\
39660.39 & 41519.69 & 42571.04 \\
39648.36 & 41538.09 & \\
39658.70 & $-<\Delta_{\mathrm{c}} u^{\circ}>a /\left(\mathrm{J} \cdot \mathrm{g}^{-1}\right)$ & \\
& $41514.5 \pm 8.5$ & $42543.4 \pm 7.7$
\end{tabular}

${ }^{a}$ Mean values and standard deviation of the mean.

Table 3. Derived Standard $\left(p^{\circ}=0.1 \mathrm{MPa}\right)$ Molar Values in the Liquid or Crystalline Phases at $T=298.15 \mathrm{~K}^{a}$

\begin{tabular}{lccr}
\hline \multicolumn{1}{c}{ compound } & \multicolumn{1}{c}{$\begin{array}{c}\Delta_{\mathrm{c}} U_{\mathrm{m}}^{\mathrm{o}}(\mathrm{cr}, 1) / \\
\mathrm{kJ} \cdot \mathrm{mol}^{-1}\end{array}$} & $\begin{array}{c}\Delta_{\mathrm{c}} H_{\mathrm{m}}^{\mathrm{o}}(\mathrm{cr}, \mathrm{l}) / \\
\mathrm{kJ} \cdot \mathrm{mol}^{-1}\end{array}$ & \multicolumn{1}{c}{$\begin{array}{c}\Delta_{\mathrm{f}} H_{\mathrm{m}}^{\mathrm{o}}(\mathrm{cr}, 1) / \\
\mathrm{kJ} \cdot \mathrm{mol}^{-1}\end{array}$} \\
\hline 4tBuPy (1) & $-5363.3 \pm 3.4$ & $-5370.1 \pm 3.4$ & $-29.4 \pm 3.6$ \\
2,6dtBuPy (1) & $-7942.4 \pm 4.0$ & $-7954.2 \pm 4.0$ & $-162.7 \pm 4.4$ \\
2,4,6ttBuPy (cr) & $-10526.2 \pm 4.9$ & $-10542.9 \pm 4.9$ & $-291.2 \pm 5.4$
\end{tabular}

${ }^{a}$ The uncertainties are twice the overall standard deviation of the mean (level of confidence 95\%).

the energy associated to the isothermal bomb process, $\Delta U$ (IBP), was calculated from eq 1 , according to ref 34 .

$$
\begin{array}{r}
\Delta U(\mathrm{IBP})=-\left\{\varepsilon_{\mathrm{cal}}+\Delta m\left(\mathrm{H}_{2} \mathrm{O}\right) c_{\mathrm{p}}\left(\mathrm{H}_{2} \mathrm{O}, 1\right)+\varepsilon_{\mathrm{f}}\right\} \Delta T_{\mathrm{ad}}+ \\
\Delta U(\mathrm{ign})
\end{array}
$$

The individual results of all combustion experiments, together with the mean values and their standard deviations, are given for each compound in Table 2. Table 3 lists the derived standard molar energies and enthalpies of combustion, $\Delta_{\mathrm{c}} U_{\mathrm{m}}^{\mathrm{o}}(1, \mathrm{cr})$ and $\Delta_{\mathrm{c}} H_{\mathrm{m}}^{\mathrm{o}}(1, \mathrm{cr})$, respectively and the standard molar enthalpies of formation for the compounds in the condensed phase, $\Delta_{\mathrm{f}} H_{\mathrm{m}}^{\mathrm{o}}(\mathrm{l}$, $\mathrm{cr}$ ), at $T=298.15 \mathrm{~K}$. In accordance with the normal thermochemical practice, ${ }^{41}$ the uncertainties assigned to the standard molar enthalpies of combustion are, in each case, twice the overall standard deviation of the mean and include the uncertainties in calibration and in the values of auxiliary quantities. To derive $\Delta_{\mathrm{f}} H_{\mathrm{m}}^{\mathrm{o}}(1, \mathrm{cr})$ from $\Delta_{\mathrm{c}} H_{\mathrm{m}}^{\mathrm{o}}(1, \mathrm{cr})$ the standard molar enthalpies of formation of $\mathrm{H}_{2} \mathrm{O}$ (l) and $\mathrm{CO}_{2}(\mathrm{~g})$, at $T=298.15$ $\mathrm{K},-(285.830 \pm 0.042) \mathrm{kJ} \cdot \mathrm{mol}^{-142}$ and $-(393.51 \pm 0.13)$ $\mathrm{kJ} \cdot \mathrm{mol}^{-1},{ }^{42}$ respectively, were used.

Measurements of the standard molar enthalpies of vaporization, $\Delta_{\mathrm{l}}^{\mathrm{g}} H_{\mathrm{m}}^{\mathrm{o}}$, or sublimation, $\Delta_{\mathrm{cr}}^{\mathrm{g}} H_{\mathrm{m}}^{\mathrm{o}}$, at $T=298.15 \mathrm{~K}$ are given in Table 4 with uncertainties of twice the standard deviation of the mean. The derived standard molar enthalpies of formation, in both the condensed and gaseous phases, for the three studied compounds, are summarized in Table 5.
Table 4. Calorimetric Values for the Standard ( $p^{\circ}=0.1 \mathrm{MPa}$ )

\begin{tabular}{|c|c|c|c|c|c|}
\hline & & $T$ & $\Delta_{\mathrm{cr}, 1,298.15 \mathrm{~K}}^{\mathrm{g}, T} H_{\mathrm{m}}^{\mathrm{o}}$ & $\Delta_{298.15 \mathrm{~K}}^{T} H_{\mathrm{m}}^{\mathrm{o}}(\mathrm{g})$ & $\begin{array}{c}\Delta_{\mathrm{cr}, 1}^{\mathrm{g}} H_{\mathrm{m}}^{\mathrm{o}} \\
(T=298.15 \mathrm{~K})\end{array}$ \\
\hline compound & expts & $\bar{K}$ & $\mathrm{~kJ} \cdot \mathrm{mol}^{-1}$ & $\mathrm{~kJ} \cdot \mathrm{mol}^{-1}$ & $\mathrm{~kJ} \cdot \mathrm{mol}^{-1}$ \\
\hline 4tBuPy (1) & 7 & 365 & $67.1 \pm 1.3$ & 12.7 & $54.4 \pm 1.3$ \\
\hline 2,6dtBuPy (1) & 7 & 324 & $64.0 \pm 1.2$ & 7.4 & $56.6 \pm 1.2$ \\
\hline $2,4,6 \mathrm{ttBuPy}(\mathrm{cr})$ & 6 & 329 & $90.2 \pm 1.7$ & 11.9 & $78.3 \pm 1.7$ \\
\hline
\end{tabular}
Molar Enthalpies of Sublimation and Vaporization at $T=298.15 \mathrm{~K}^{a}$

${ }^{a}$ The uncertainties are twice the overall standard deviation of the mean (level of confidence 95\%).

Table 5. Derived Standard $\left(p^{\circ}=0.1 \mathrm{MPa}\right)$ Molar Enthalpies of Formation at $T=298.15 \mathrm{~K}^{a}$

\begin{tabular}{lccr}
\hline \multicolumn{1}{c}{ compound } & $\begin{array}{c}\Delta_{\mathrm{f}} H_{\mathrm{m}}^{\mathrm{o}}(\mathrm{cr}, 1) / \\
\mathrm{kJ} \cdot \mathrm{mol}^{-1}\end{array}$ & $\begin{array}{c}\Delta_{\mathrm{cr} .1}^{\mathrm{g}} H_{\mathrm{m}}^{\mathrm{o}} / \\
\mathrm{kJ}^{\prime} \cdot \mathrm{mol}^{-1}\end{array}$ & \multicolumn{1}{c}{$\begin{array}{c}\Delta_{\mathrm{f}} H_{\mathrm{m}}^{\mathrm{o}}(\mathrm{g}) / \\
\mathrm{kJ} \cdot \mathrm{mol}^{-1}\end{array}$} \\
\hline 4tBuPy (1) & $-29.4 \pm 3.6$ & $54.4 \pm 1.3$ & $25.0 \pm 3.8$ \\
2,6dtBuPy (1) & $-162.7 \pm 4.4$ & $56.6 \pm 1.2$ & $-105.5 \pm 4.6$ \\
$2,4,6 \mathrm{ttBuPy}(\mathrm{cr})$ & $-291.2 \pm 5.4$ & $78.3 \pm 1.7$ & $-211.4 \pm 5.7$ \\
${ }^{a}$ The uncertainties & are twice the overall standard deviation of the \\
mean (level of confidence 95\%).
\end{tabular}

Table 6. Comparison of Values of Enthalpy of Formation in the Gaseous State at $T=298 \mathrm{~K}$ Measured in This Work with Literature Values

\begin{tabular}{lcc}
\hline \multicolumn{1}{c}{ compound } & $\Delta_{\mathrm{f}} H_{\mathrm{m}}^{\mathrm{o}}(\mathrm{g}) / \mathrm{kJ} \cdot \mathrm{mol}^{-1}$ & $\delta$-increment $/ \mathrm{kJ} \cdot \mathrm{mol}^{-1}$ \\
\hline Py & $140.4 \pm 0.7^{43}$ & \\
4tBuPy & $25.0 \pm 3.8^{a}$ & $-115.4 \pm 3.9$ \\
$2,6 \mathrm{dtBuPy}$ & $-105.5 \pm 4.6^{a}$ & $-245.9 \pm 4.7$ \\
2,4,6ttBuPy & $-211.4 \pm 5.7^{a}$ & $-351.8 \pm 5.7$ \\
4MePy & $104.0 \pm 0.9^{43}$ & $-36.4 \pm 1.1$ \\
$2,6 \mathrm{dMePy}$ & $58.1 \pm 1.5^{43}$ & $-82.3 \pm 1.7$ \\
$2,4,6$ tMePy & $19.3 \pm 2.4^{6}$ & $-121.1 \pm 2.5$ \\
${ }^{a}$ This work. & &
\end{tabular}

\section{Discussion}

The energetic contributions associated with the substitution of tert-butyl (tBu) groups on positions 4-,2,6- and 2,4,6- of the basic structure (pyridine, Py) can be evaluated from the results obtained in this work and compared with the corresponding effects observed for identical substitutions of methyl (Me) groups. Table 6 contains all the necessary literature values, together with the results obtained in the present study, and lists the enthalpic increment, $\delta$, to the standard molar enthalpies of formation in the gaseous state for the substitution of one, two, and three $(\mathrm{X}=\mathrm{Me}$ or $\mathrm{tBu})$ groups into the pyridine ring $(\mathrm{Py})$.

$$
\begin{array}{r}
\delta \text {-increment }=\Delta_{\mathrm{f}} H_{\mathrm{m}}^{\mathrm{o}}\left(\mathrm{X}_{n} \mathrm{Py}, \mathrm{g}\right)-\Delta_{\mathrm{f}} H_{\mathrm{m}}^{\mathrm{o}}(\mathrm{Py}, \mathrm{g}) \\
n=1,2, \text { or } 3
\end{array}
$$

The effect of both alkyl substituents in the ortho and para positions on the gas phase enthalpies of formation is that both substituents increase the stability of the molecule relative to hydrogen. Ribeiro da Silva ${ }^{3}$ showed in terms of increments and within the experimental uncertainty that the enthalpy of formation of gaseous 2,4,6-trimethylpyridine $(2,4,6 \mathrm{tMePy})$ could be obtained from the value of the enthalpy of formation of gaseous pyridine, adding the enthalpic increments for 4-methylpyridine (4MePy) and 2,6-dimethylpyridine (2,6dMePy) relatively to pyridine. For the tert-butyl compounds studied in the present work, identical treatment leads to the value $-(220.9 \pm 6.1) \mathrm{kJ}$ $\mathrm{mol}^{-1}$ for the enthalpy of formation of gaseous 2,4,6-tri-tertbutylpyridine. Although the experimental value $-(211.4 \pm 5.7)$ $\mathrm{kJ} \mathrm{mol}^{-1}$ is close to the estimated value, it points to a relative instability of the 2,4,6ttBuPy molecule that can be explained by the steric effects of the two hindered substituents adjacent to the nitrogen atom, since the steric requirement of the tert- 
butyl groups are such that substituents at the positions 2 and 6 are incapable of achieving a conformation which minimizes stereochemical interactions.

Our conclusion is enforced by the studies of other researchers ${ }^{44,45}$ since the compound 2,6-di-tert-butylpyridine exhibits unusual reduced basicity, even being mentioned as a nonnucleophilic base. An explanation proposed for this feature is the fact that there is a stereochemical barrier which hinders the addition of the proton to the basic center.

\section{Literature Cited}

(1) Vollhardt, K. P. C.; Schore, N. E. Organic Chemistry, 3rd edition; W. H. Freeman and Company: New York, 1999.

(2) Baird, C. Environmental Chemistry, 2nd edition; W. H. Freeman and Company: NewYork, 1999.

(3) Ribeiro da Silva, M. A. V.; Matos, M. A. R. Recent work on the thermochemistry of some nitrogen heterocycles. Pure Appl. Chem. 1997, 69, 2295-2305.

(4) Ribeiro da Silva, M. A. V.; Matos, M. A. R.; Rio, C. M. A. Standard molar enthalpy of formation of 2,4,6-trimethylpyridine. J. Chem. Thermodyn. 1997, 29, 901-906.

(5) Ribeiro da Silva, M. A. V.; Matos, M. A. R.; Amaral, M. L. P. F. Standard molar enthalpies of formation of some chloropyridines. J. Chem. Thermodyn. 1997, 29, 1535-1543.

(6) Ribeiro da Silva, M. A. V.; Matos, M. A. R.; Rio, C. M. A.; Morais, V. M. F. Thermochemical and theoretical studies of 4-methylbiphenyl, 4,4'-dimethylbiphenyl, 4,4'-dimethyl-2,2'-bipyridine. J. Chem. Soc., Faraday Trans. 1997, 93, 3061-3065.

(7) Ribeiro da Silva, M. D. M. C.; Matos, M. A. R.; Vaz, M. C.; Santos, L. M. B. F.; Pilcher, G.; Acree Jr, W. E.; Powell, J. R. Enthalpies of combustion of the pyridine N-oxide derivatives: 4-methyl-, 3-cyano-, 4-cyano-, 3-hydroxy-, 2-carboxy-, 4-carboxy-, and 3-methyl-4-nitro, and of the pyridine derivatives: 2-carboxy-, and 4-carboxy-. The dissociation enthalpies of the N-O bonds. J. Chem. Thermodyn. 1998, $30,869-878$.

(8) Ribeiro da Silva, M. A. V. Thermochemistry of substituted pyridines and analogous heterocycles: the enthalpic increments for a group additivity scheme. Pure Appl. Chem. 1999, 71, 1257-1265.

(9) Ribeiro da Silva, M. A. V.; Matos, M. A. R.; Rio, C. A.; Morais, V. M. F.; Wang, J.; Nichols, G.; Chickos, J. S. A Thermochemical and Theoretical Study of the Phenylpyridine Isomers. J. Phys. Chem. A 2000, 104, 1774-1778.

(10) Ribeiro da Silva, M D. M. C.; Gonçalves, J. M., Jr. Standard molar enthalpy of sublimation of crystalline 3-pyridinecarboxylic acid. J. Chem. Thermodyn. 2000, 32, 1071-1073.

(11) Ribeiro da Silva, M. D. M. C.; Gonçalves, J. M.; Ferreira, S. C. C.; da Silva, L. C. M.; Sottomayor, M. J.; Pilcher, G., Jr.; Roy, L. E. Experimental the rmochemical study of the enthalpies of formation and sublimation of isonicotinamide, picolinamide, nicotinamide, isonicotinamide $\mathrm{N}$-oxide, and nicotinamide $\mathrm{N}$-oxide. The dissociation enthalpies of the N-O > bonds. J. Chem. Thermodyn. 2001, 33, 12631275 .

(12) Morais, V. M. F.; Miranda, M. S.; Matos, M. A. R. Thermochemical study of the ethylpyridine and ethylpyrazine isomers. Org. Biomol. Chem. 2003, 1, 4329-4334.

(13) Gomes, J. R. B.; Amaral, L. M. P. F.; Ribeiro da Silva, M. A. V. Gas-phase thermochemistry of chloropyridines. Chem. Phys. Lett. 2005, 406, 154-160.

(14) Matos, M. A. R.; Morais, V. M. F.; Ribeiro da Silva, M. D. M. C.; Marques, M. C. F.; Sousa, E. A.; Castiñeiras, J. P.; Santos, C. P., Jr. Thermochemical and Theoretical Studies of Dimethylpyridine-2,6dicarboxylate and Pyridine-2,3-, Pyridine-2,5-, and Pyridine-2,6dicarboxylic Acids. J. Chem. Eng. Data 2005, 50, 1184-1191.

(15) Morais, V. M. F.; Miranda, M. S.; Matos, M. A. R. Experimental and computational thermochemistry of the dihydroxypyridine isomers. J. Chem. Thermodyn. 2006, 38, 450-454.

(16) Freitas, V. L. S.; Oliveira, L. I. P.; Ribeiro da Silva, M. D. M. C. Standard molar enthalpies of formation of the acetylpyridine isomers. J. Chem. Thermodyn. 2007, 39, 39-43.

(17) Ribeiro da Silva, M. D. M. C.; Freitas, V. L. S.; Santos, L. M. N. B F.; Fulem, M.; Sottomayor, M. J.; Monte, M. J. S.; Acree, W. E., Jr. Thermodynamic properties of three pyridine carboxylic acid methyl ester isomers. J. Chem. Eng. Data 2007, 52, 580-585.

(18) Acree, Jr, W. E.; Pilcher, G.; Ribeiro da Silva, M. D. M. C. The dissociation enthalpies of terminal N-O. bonds in organic compounds. J. Phys. Chem. Ref. Data 2005, 34, 553-572.

(19) Boschloo, G.; Hagfeldt, A.; Haggman, L. Quantification of the effect of 4-tert-butylpyridine addition to $\mathrm{I}^{-} / \mathrm{I}_{3}{ }^{-}$redox electrolytes in dyesensitized nanostructured $\mathrm{TiO}_{2}$ solar cells. J. Phys. Chem. B 2006 110, 13144-13150.
(20) Shi, C.; Dai, S.; Wang, K.; Pan, X.; Kong, F.; Hu, L. The adsorption of 4-tert-butylpyridine on the nanocrystalline $\mathrm{TiO}_{2}$ and Raman spectra of dye sensitized solar cells in situ. Vib. Spectrosc 2005, 39, 99-105.

(21) Mikoshiba, S.; Murai, S.; Sumino, H.; Hayase, S. Another role of LiI/ tert-butylpyridine in room-temperature molten salt electrolytes containing water for dye sensitized solar cell. Chem. Lett. 2002, 31, 11561157.

(22) Grätzel, M.; O'Regan, B. A low-cost, high-efficiency solar cell based on dye sensitized colloidal TiO2 films. Nature 1991, 353, 737-740.

(23) Bach, U.; Lupo, D.; Comte, P.; Moser, J. E.; Weissörtel, F.; Salbeck, J.; Spreitzert, H.; Grätzel, M. Solid-state dye-sensitized mesoporous $\mathrm{TiO}_{2}$ solar cells with high photon-to-electron conversion efficiencies. Nature 1998, 395, 583-585.

(24) Grätzel, M. Photoelectrochemical cells. Nature 2001, 414, 338-344.

(25) http://patents.ic.gc.ca/cipo/cpd/en/patent/2113456/summary.html.

(26) http://aldrich.com.

(27) Gundry, H. A.; Harrop, D.; Head, A. J.; Lewis, G. B. Thermodynamic properties of organic oxygen compounds 21 . Enthalpies of combustion of benzoic acid, pentan-1-ol, octan-1-ol, and hexadecane-1-ol. J. Chem. Thermodyn. 1969, 1, 321-332.

(28) Bickerton, J.; Pilcher, G.; Al-Takhin, G. Enthalpies of combustion of the three aminopyridines and the three cyanopyridines. J. Chem. Thermodyn. 1984, 16, 373-378.

(29) Ribeiro da Silva, M. D. M. C.; Santos, L. M. N. B. F.; Silva, A. L. R.; Fernandes, O.; Acree, W. E., Jr. Energies of 6-methoxyquinoline and 6-methoxyquinoline $\mathrm{N}$-oxide: the dissociation enthalpy oh the $(\mathrm{N}-\mathrm{O})$. bond. J. Chem. Thermodyn. 2003, 35, 1093-1100.

(30) Skinner, H. A.; Snelson, A. The heats of combustion of the four isomeric butyl alcohols. Trans. Faraday Soc. 1960, 56, 1776-1783.

(31) Wagman, D. D.; Evans, W. H.; Parker, V. B.; Schumm, R. H.; Halow, I.; Bailey, S. M.; Churney, K. L.; Nutall, R. The NBS Tables of Chemical Thermodynamic Properties. J. Phys. Chem. Ref. Data 1982, II, Suppl. 2.

(32) Coops, J.; Jessup, R. S.; Van Nes, K. Calibration for reactions in a bomb at constant volume. In Experimental Thermochemistry; Rossini, F. D.,. Ed; Interscience: New York, 1956; Vol. 1, pp 27-58.

(33) Washburn, E. W. Standard states for bomb calorimetry. J. Res. Nat. Bur. Stand. (U.S.). 1933, 10, 525-558.

(34) Hubbard, W. N.; Scott, D. W.; Waddington, G. Standard states and corrections for combustions in a bomb at constant volume. In Experimental Thermochemistry; Rossini, F. D., Ed; Interscience: New York,: 1956: Vol. 1, pp 75-127.

(35) Ribeiro da Silva, M. A. V.; Matos, M. A. R.; Amaral, L. M. P. F. Thermochemical study of 2-, 4-, 6-, and 8-methylquinoline. J. Chem. Thermodyn. 1995, 27, 565-574.

(36) Adedeji, F. A.; Lalage, D.; Brown, D. L. S.; Connor, J. A.; Leung, M.; Paz Andrade, M. I.; Skinner, H. A. Thermochemistry of arene chromium tricarbonyls and the strengths of arene-chromium bonds. J. Organomet. Chem. 1975, 97, 221-228.

(37) Stull, D. R.; Westrum, E. F.; Sinke, G. C. The Chemical Thermodynamics of Organic Compounds, Wiley: New York, 1969.

(38) Chickos, J. S.; Acree, W. E., Jr. Enthalpies of vaporization of organic and organometallic compounds, 1880-2002. J. Phys. Chem. Ref. Data 2003, 32, 519-878.

(39) Chickos, J. S., Jr. Enthalpies of sublimation of organic and organometallic compounds, 1910-2001. J. Phys. Chem. Ref. Data 2002, 31, 537-698.

(40) Wieser, M. E. Atomic weights of the elements 2005 (IUPAC Technical Report). Pure Appl. Chem. 2006, 78, 2051-2066.

(41) Rossini, F. D. Assignment of Uncertainties to Thermochemical Data. In Experimental Thermochemistry; Rossini, F. D., Ed; Interscience: New York, 1956; Vol. 1, pp 297-319.

(42) CODATA recommended key values for thermodynamics. J. Chem. Thermodyn. 1978, 10, 903-906.

(43) Pedley, J. B. Thermochemical Data and Structures of Organic Compounds, Vol 1; Thermodynamics Research Center: College Station, Texas, 1994

(44) Brown, H. C.; Kanner, B. Preparation and reactions of 2,6-Di-tbutylpyridine and related hindered bases. A case of steric hindrance toward the proton. J. Am. Chem. Soc. 1966, 88, 986-992.

(45) Meot-Ner, M.; Sieck, L. W. The ionic hydrogen bond. 1. Sterically hindered bonds. Solvation and Clustering of protonated amines and pyridines. J. Am. Chem. Soc. 1983, 105, 2956-2961.

Received for review March 3, 2008. Accepted April 23, 2008. Thanks are due to Fundação para a Ciência e a Tecnologia, Lisbon, Portugal, for financial support to Centro de Investigação em Química of the University of Porto.

JE800155Q 